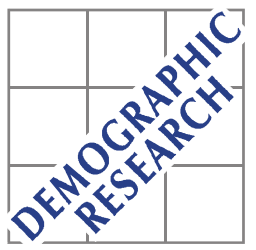

Demographic Research a free, expedited, online journal of peer-reviewed research and commentary in the population sciences published by the Max Planck Institute for Demographic Research Konrad-Zuse Str. 1, D-18057 Rostock · GERMANY www.demographic-research.org

DEMOGRAPHIC RESEARCH

VOLUME 27, ARTICLE 22, PAGES 645-680 PUBLISHED 13 NOVEMBER 2012

http://www.demographic-research.org/Volumes/Vol27/22/

DOI: 10.4054/DemRes.2012.27.22

Research Article

\title{
Further evidence of community education effects on fertility in sub-Saharan Africa
}

\section{Øystein Kravdal}

\section{(C) 2012 Øystein Kravdal.}

This open-access work is published under the terms of the Creative Commons Attribution NonCommercial License 2.0 Germany, which permits use, reproduction \& distribution in any medium for non-commercial purposes, provided the original author(s) and source are given credit.

See http:// creativecommons.org/licenses/by-nc/2.0/de/ 


\section{Table of Contents}

1 Introduction $\quad 646$

$2 \quad$ Theoretical considerations $\quad 648$

2.1 A brief review of the importance of individual education 648

$\begin{array}{ll}2.2 & \text { Possible effects of community education }\end{array}$

2.3 Selection 650

2.4 Conditional effects of community education 650

3 Data 651

3.1 Weights 652

3.2 Levels of aggregation and measures of community education 652

$3.3 \quad$ GPS data 653

3.4 Further details about the data used in the different parts of the 654 analysis

$4 \quad$ Methods 655

$4.1 \quad$ Included variables $\quad 657$

4.2 Potential problems arising because of measurements at interview 659

4.3 Selection into higher parities $\quad 659$

$5 \quad$ Results $\quad 660$

$5.1 \quad$ Change over time $\quad 660$

$5.2 \quad$ Conditional effects 664

5.3 Controlling for constant unobservables at a level slightly higher than 665

$5.4 \quad$ Effects of average education in a larger area 667

6 Conclusion $\quad 669$

$7 \quad$ Acknowledgements $\quad 671$

$\begin{array}{ll}\text { References } & 672\end{array}$

$\begin{array}{ll}\text { Appendix } & 676\end{array}$ 


\title{
Further evidence of community education effects on fertility in sub-Saharan Africa
}

\author{
Øystein Kravdal ${ }^{1}$
}

\begin{abstract}
BACKGROUND

Earlier investigations have shown associations between a woman's chance of having a child, or various proximate determinants of her fertility, and the socioeconomic resources in the community in which she lives, net of her own resources.

\section{OBJECTIVES AND METHODS}

This study, which is based on DHS surveys from 28 countries in sub-Saharan Africa, adds to the knowledge about this issue. With a focus on first- and higher-order birth rates, four specific questions are addressed.
\end{abstract}

\section{RESULTS AND CONCLUSIONS}

One result is that the negative associations between a woman's birth rate and the average education in the census enumeration area in which she lives, net of her own education, have remained stable or become stronger over the last decade. Second, these associations are most pronounced among women who score high on indicators of socioeconomic development which suggests that they may become further strengthened. Third, associations even appear when a fixed-effects approach - based on data from two DHS surveys with GPS coordinates in each country - is employed to control for unobserved constant characteristics of units at a slightly higher level than the census enumeration area. Fourth, local processes seem to be particularly important: education among women in the province or nearest census enumeration areas is not inversely associated with fertility.

\footnotetext{
${ }^{1}$ University of Oslo. E-mail: okravdal@econ.uio.no.
} 


\section{Introduction}

A large number of studies from many different countries have shown an inverse relationship between a woman's educational attainment and her fertility (e.g. United Nations 2004). In addition, it has been concluded in some recent studies from subSaharan Africa that, when women with the same level of education are compared, those who live in communities where others have relatively high education tend to have the lowest fertility (Kravdal 2002; DeRose and Kravdal 2007). Such associations that are indicative of externality effects of education have also been reported in fertility studies from other regions (Hirschman and Young 2000) and in investigations of fertility desires (Moursund and Kravdal 2003; Baschieri 2007) or contraceptive use (Benefo 2006, 2010; DeRose, Wu, and Dodoo 2010; McNay et al. 2003; Moursund and Kravdal 2003; Stephenson et al. 2007; Stephenson, Beke, and Tshibangu 2008) in various developing countries, with a variety of additional factors included (more or less appropriately) in the models. There are also studies, however, where associations have not shown up (Gupta and Mahy 2003; Yabiku 2006). Similarly, community socioeconomic resources may affect individual health and mortality. More attention has been devoted to this subject over the last couple of decades, especially in rich countries (e.g. Pickett and Pearl 2001; Chaix, Rosvall, and Merlo 2007; Turrell et al. 2007), though some work has also been done in poor settings (e.g. Kravdal 2004; Pamuk, Fuchs, and Lutz 2011).

This type of externality or aggregate-level effect would have important implications: if education in a society is expanded, fertility will be reduced not only because a larger proportion of women enter into educational categories associated with lower fertility but also because everyone is affected regardless of their own education. In individual-level models, the coefficient for the woman's own education picks up

only part of this community-level effect, which contributes to an underestimation of the total impact of educational investments (Kravdal 2002). That said, the coefficients for education (at individual as well as aggregate level) may, at the same time, overstate the education effects because of inadequate control for factors that tend to increase education while pushing fertility down.

The overarching goal of this study is to learn more about how community education affects fertility above and beyond the effect of the woman's own education. Using data from Demographic and Health Surveys (DHS) in 28 countries in subSaharan Africa, much of the analysis is focused on effects of the average education in the census enumeration area (CEA) where the woman lives (see motivation of this measure below). More specifically, one objective is to find out whether the associations between this "CEA education" (wording used in remaining text for simplicity) and an individual woman's chances of having a child have changed over the most recent 
decade, using data from countries that have had a recent survey and another survey about ten years earlier. Additionally, the most recent surveys from all 28 countries are used to produce estimates of the relationship between fertility and CEA education that are as representative as possible for the current population in the region.

Another goal is to assess the potential for future change as countries undergo further socioeconomic development. Some of the mechanisms that community education has been thought to operate through may become less relevant in a better educated and more urbanized society while others could become more relevant. Using data from the most recent surveys in all countries, the conditioning effects of five indicators of socioeconomic development are examined.

Only a few other studies have investigated time trends: Nahmias and Stecklov (2007) reported an increasingly strong relationship between community education and number of children born among Palestinians in Israel while DeRose, $\mathrm{Wu}$, and Dodoo (2010) showed a diminishing association between contraceptive use and province-level education in Ghana, given the partners' fertility intentions No attempt has been made to assess the conditioning effect of modernization.

The third goal of the study is to check whether there are also associations with CEA education when it is controlled for constant unobserved factors at approximately that level in a fixed-effects approach. Having multiple measurements in each CEA would be the ideal design, but few countries have had DHS surveys with such a sampling plan. The strategy in this study has instead been to find CEAs in two subsequent surveys that are geographically close to each other (using GPS coordinates) and consider these as representing one area with certain constant unobserved characteristics of potential importance for fertility and education.

Fourth, the study takes education at different levels of aggregation into account. Presumably, a woman's fertility is influenced by the level of education among neighbours, others in the CEA, and people in a larger area. For example, although direct communication primarily is with individuals who do not live far away, those individuals in turn interact with others so that a larger chain of influential people within a broader area is involved. Furthermore, to the extent that a woman's work opportunities or access to health services are affected by the resources of others, a rather high level of aggregation may be most relevant. In this study, both CEA education and province education are included in some models to see whether associations with one are stronger than with the other. Attempts to separate these associations have not been made earlier. Additionally, some models include the average education in neighbouring CEAs (identified by using GPS coordinates) instead of province education. 


\section{Theoretical considerations}

Below, some pathways that a woman's own education may operate through in affecting her fertility are briefly reviewed. While individual-level effects of education are not in focus of the study, these arguments serve as a backdrop for the discussion of why community education may also be important. Next, the possibility of selection is addressed, and the potentially conditioning effects of the level of socioeconomic development are discussed.

\subsection{A brief review of the importance of individual education}

There are many reasons why a woman's birth rate is usually inversely related to the length of her education, at least above a certain level. One reason is that net costs of childbearing and -rearing may be relatively high among the better-educated, especially because they also want their children to go to school (which may be costly and would make children less available for domestic and agricultural work) and because their opportunity costs of having children are high. Furthermore, the better-educated may have stronger preferences for other sources of satisfaction; they typically experience lower infant and child mortality, and they may have more knowledge about and be more accepting of modern contraception. On the other hand, a higher purchasing power resulting from own work or marriage into a relatively rich family may (unless childbearing costs are correspondingly increased) push fertility up, and the better educated may also be less strongly influenced by fertility-depressing norms about breastfeeding and post-partum sexual abstinence. Some of these potential effects of education may be primarily due to literacy or more specific practical or theoretical skills obtained through schooling, while others may also involve an education-induced strengthening of the woman's position relative to men. ${ }^{2}$

The details in some of these mechanisms may vary between first- and higher-order births because, to a particular extent, the former involves decisions about whether one should have a child sooner rather than later (Happel, Hill, and Low 1984). ${ }^{3}$ In addition,

\footnotetext{
${ }^{2}$ While a woman's degree of autonomy (also affecting fertility through other channels than mentioned above; see e.g. Mason 1998 or Dodoo and Frost 2008) is probably determined by community norms and institutional structures to a large extent, there may also be some influence from her own education (e.g. Niraula and Morgan 1996), though that effect is not necessarily always positive (Balk 1994).

${ }^{3}$ For example, while high costs of childbearing are a relevant factor also in such timing decisions, the argument is somewhat more complex than for fertility quantum. Assuming constraints on borrowing, a couple may want to postpone childbearing costs until a higher age, when the income presumably will be higher. This would be especially important if the costs are high. Another issue is that the short- and long-term childbearing costs may depend on the first-birth timing.
} 
some of the suggested arguments are simply not relevant for women who have not already had a child, while others may be added because entry into parenthood is closely related to union formation, which also involves other determinants. All in all, it would therefore make good sense to estimate models separately for first and later births.

\subsection{Possible effects of community education}

Many of the causally more proximate determinants of fertility such as those mentioned above may be influenced not only by the woman's own education but also by the education of other individuals in the community. One reason is the social interaction that takes place (e.g., Montgomery and Casterline 1996). For example, a woman may learn about contraception or prevention of child diseases from well-educated (male or female) neighbours, or discussions with these neighbours may make her less accepting of traditional ideas about breastfeeding. Furthermore, she may plan to send her children to school because she has learned that this is a wise strategy, or because she simply wants to do as others do to gain their approval or avoid sanctions.

Another possible causal pathway is that the overall educational level among other individuals may have broad structural effects of importance to everyone. For example, with a more educated population more jobs in the modern sector may be created and especially if women's general level of education is high - it may be seen as more acceptable for women to have such jobs. Because this type of work usually is difficult to combine with responsibility for young children, opportunity costs of childbearing will be high. On the other hand, with many well-educated women in the community there is also more competition for a given number of jobs. This would suggest relatively low opportunity costs. In other words, a key issue is whether the number of jobs increases in step with the expansion of education.

A modernization of the economy driven in part by education will typically also lead to higher incomes for men (the women's husbands) and more wealth accumulation - with ambiguous effects on fertility - and a lower value of child labour. Furthermore, a woman's degree of autonomy may depend on the degree of autonomy among other women in the community, which in turn may be influenced by their overall level of education. Finally, the access to high-quality family planning and other health services (affecting regulation costs and child mortality) is probably partly a result of attitudes, levels of knowledge, and incomes in the community, which in turn are influenced by the general educational level.

Some of these possible mechanisms involve individuals nearby, but these individuals communicate with others who in turn communicate with others, so that a larger community is involved. Other mechanisms probably play out at a relatively high 
level of aggregation. For example, work opportunities and access to health care may depend especially on the level of education in a larger area. It is therefore not obvious how "community education" should be operationalized in an analysis. Another problem is the accumulative nature of many of the mechanisms, which has the consequence that, for a woman who lives in a certain community at a certain point in time, the chance of having a child is probably affected by earlier educational levels in this community as well as educational levels in communities where she has lived earlier (if she has moved). This complexity is, in practice, very difficult to capture.

\subsection{Selection}

An observed relationship between community education and individual fertility may not only be the result of causal effects such as those just mentioned but also joint community-level determinants. For example, educational levels may be relatively high in or near urban areas, where there may also be low fertility for other reasons. Furthermore, high educational levels may be the result partly of relatively high incomes in the community several years earlier, when the currently-observed adults were of school age, as well as positive attitudes to education among politicians and the public at that time. These attitudes may, in turn, reflect the size of the non-agricultural sector and thus the need for a more skilled labour force. Attitudes to girls' education in particular may be linked to ideas about women's rights and obligations more generally as well as the prevailing family system (especially whether adult daughters are supposed to support their parents or their in-laws). In addition, a currently high income level, a large non-agricultural sector, and modern attitudes to women in a particular area- all with potential effects on fertility - may attract educated women to move to or remain there.

A relationship between community education and fertility may also be produced by individual characteristics linked to migration: women or men who move to or remain in communities where the educational level is high may have attitudes or resources that also have implications for their fertility.

\subsection{Conditional effects of community education}

The effect of community education on individual fertility may vary with a number of factors including the level of socioeconomic development (and there may be a similar variation in the selection pathways). For example, in a society where many adults have some education and the general level of knowledge is relatively high, learning from other women about contraception or the value of sending children to school is a less 
relevant mechanism. That said, there are other types of knowledge and ideas that can be spread. Another issue is that the intensity of the social interaction may depend on population density, though it is not obvious whether the short distance to neighbours in urban areas reduces the amount of social interaction (Brueckner and Largey 2008) or has the opposite impact (Putnam 2000).

Opportunity cost effects may also vary with the level of socioeconomic development, though it is hard to predict the direction of this interaction as well. While it is possible that increases in education will have a particularly modest impact on the number of jobs in the modern sector in rural settings with an initially dominant agricultural sector (as mentioned by Baschieri 2007), such a pattern is far from obvious. Another possible contribution to an interactive effect is that the impact of a higher educational level on women's general level of autonomy may depend on the educational level at the outset (e.g., Jejeebhoy and Sathar 2001).

Furthermore, in a more developed setting with more exposure to mass media, women may have more knowledge about society outside the nearest neighbourhood. This will make any effect of the educational level in that area more relevant regarding job opportunities, access to family planning services, or availability of health care.

Another type of argument is that it may be particularly difficult to define a meaningful "influential community" in an urban environment. More specifically, a CEA (the unit used in this and several other studies) may, in the countryside, include one or a few villages, and the distance to another village may be so large that people may be rather modestly influenced by the resources there. The situation is probably quite different if the border of the CEA goes through a very densely populated area (as pointed out by Hobcraft 2006). In that case, a woman is particularly likely to be influenced by a combination of the characteristics of the CEA where she lives and those of surrounding CEAs. If these characteristics are not strongly correlated, a weaker effect of the characteristics of the CEA where the woman lives may be observed.

An alternative line of reasoning is that neighbouring CEAs may be equally important in urban and rural areas, but the degree of clustering varies (Kravdal 2009). For example, if there is a stronger clustering in urban areas (i.e., a stronger correlation between average education in CEAs that are close to each other), the estimated effect of the education in the CEA where the woman lives will also be stronger.

\section{Data}

The analysis is based on data from Demographic and Health Surveys in 28 countries in sub-Saharan Africa. These surveys used a clustered sample. Each province, governorate, or similar administrative level of a country was divided into small areas 
that may be referred to as census enumeration areas (CEAs). These CEAs span one or a few villages or settlements, a small town, or part of a larger town or city (Macro International 1996), and they typically include about 1000 people of whom about one quarter are women of reproductive age. Some of these CEAs were then selected randomly to be representative of the province or their urban and rural parts. Within each selected CEA, about 25 households were randomly selected, and all women of reproductive age (15-49) in the household were interviewed.

\subsection{Weights}

Some provinces, or urban and rural parts of provinces, are more strongly represented in the surveys than others so weights are included in the DHS data. These weights are referred to below as "province-specific" and were used in all parts of the analysis (though it had little impact on estimates; see note to Table 3).

When data from several countries are pooled, one may also consider using country-specific weights. One potential problem from the perspective of this analysis is that there are quite large differences in survey sizes within a country (unrelated to the country's population growth). When comparing estimates over the ten-year period, the province-specific weights in the earliest set of surveys were therefore multiplied by country-specific coefficients defined so that each country contributed as much to the results for these years as it did for the most recent years (though this procedure actually changed estimates by less than $10 \%$ ). In another part of the analysis, country-specific coefficients were instead used to make each country count according to its relative population size (e.g., large coefficient for Nigeria and small for Swaziland). Whenever weights were used they were normalized so that the weighted number of observations equaled the actual number of observations.

\subsection{Levels of aggregation and measures of community education}

As mentioned earlier, it is not obvious what the most relevant level of aggregation would be when assessing effects of community education. In this analysis, three levels have been used: the CEAs (in most of the models), the provinces, and an intermediate level further defined below. It may well be that some subgroups of women in a CEA are more influential than others through the direct or indirect social interaction processes or other mechanisms. Lacking knowledge about this, it seems reasonable to focus on the average over all women in the CEA - regardless of factors such as their age or social 
position. ${ }^{4}$ This average is not reported in the DHS data, but the average (mean) over all female respondents in the CEA (i.e., a random sample of typically about $10 \%$ ) was used as a proxy in the analysis. Simulation experiments have shown that the bias introduced by this is very small (Kravdal 2006). Excluding the individual under consideration when calculating the average had no impact on results. Average education among men might also be associated with fertility but was disregarded for simplicity because it is closely correlated with that among women (and also less well-measured).

\subsection{GPS data}

To protect the anonymity of the respondents the CEAs in the DHS surveys are not identified by name. Each of them is assigned a number, however, and in some of the surveys spatial co-ordinates in the Global Position System (GPS) are available to researchers. These coordinates refer to a point randomly displaced (up to five and, in a few cases, ten kilometers in rural areas, and up to two kilometers in urban areas) compared to the center of the CEA. By using these coordinates, it is possible to calculate approximate distances between all CEAs in a survey and thus also, for any given CEA, find a group of CEAs (defined by numbers) located within a certain distance (with some error because of the random displacement). Surveys where many CEAs were assigned the same GPS coordinates were not included in the parts of the analysis that relied on GPS co-ordinates.

\footnotetext{
${ }^{4}$ Other community education indicators might be worth trying in future research. For example, a woman may interact primarily with women whose educational level is not very different from her own and also care less about the behaviour and attitudes of those who are more different. This could be operationalized by a womanspecific average where those who are most different from her are left out of the calculation. A complicating factor is that, for example, those with highest education among this group of peers may themselves communicate with women who have more education. Furthermore, for the social interaction that involves learning, women with higher education than the individual under consideration may be particularly important; there would be less to learn from the others. Thus, it could make sense to include only these better educated women when calculating the average. Also, it is possible that the variation in education among the other women somehow matters. Large variation may signal tolerance for variation in behaviour more generally and thus weaken the inclination to imitate fertility-related behaviour, or it may result in less communication among the others because they may consider each other as having very different lives. The latter means a lower "network density," which has been claimed to weaken the pressure to conform (Kohler, Behrman, and Watkins 2001). Variation may play a different role in "social learning" than in "social influence," however. Finally, the individual woman's job opportunities may be affected to a particular extent by her ranking in educational distribution, so that one might consider including the proportion with higher education than her in the model.
} 


\subsection{Further details about the data used in the different parts of the analysis}

Different groups of surveys were selected for the different research questions. When assessing the change over time, a group of surveys referred to as Group A was used. It includes the most recent survey and a survey 8-13 years earlier for each country that have had two such surveys, unless the most recent survey was before 2002. The 16 countries that are represented in this group of surveys are listed in the Appendix table. There were 4,347 CEAs in the earliest surveys and 6,936 in the most recent.

Survey Group B includes the most recent survey from each country, except if this was before 2002, and was used to produce estimates that are as representative of the current population in the region as possible. It was also used when examining the conditioning effects of five indicators of socioeconomic development (defined below) and to see whether there was an independent association with province education. Twenty-eight countries were represented in this survey group (again, see Appendix table) which included 11,800 CEAs in 283 provinces.

Survey Group C includes the two most recent surveys with GPS coordinates of good quality (meaning that there are not many CEAs with the same coordinates) from each of the 14 countries that have had two such surveys, the most recent being in 2002 or later. Each CEA in the earliest survey was paired with the most proximate CEA in the later survey in the same country. ${ }^{5}$ There were 11,095 CEAs in these surveys but because the number of CEAs was not the same in the two surveys within a country and GPS coordinates were missing for some CEAs, only 4,656 pairs of CEAs were constructed. The analysis was further restricted to the pairs that included 25 or more six-month observations (see definition below) because there were convergence problems when there were fewer observations. There were 4,639 such pairs in the analysis of second and higher-order births and 4,223 in the analysis of first- and higherorder births.

The underlying idea of this approach is that, with a lack of measurements in the same CEAs, pairs of CEAs that are close to each other can be considered as representing one unit at a somewhat higher level of aggregation. To control for constant unobserved factors at that level, one dummy ("fixed effect") for each pair was included in the models. (See comments on selection above and brief further discussion of model motivation below.) Obviously, a pair of CEAs should only be included in such an analysis if the distance between the two CEAs is not too large. The following limits were set: $5 \mathrm{~km}(1,315$ pairs in the analysis of first births and 1,394 pairs in the analysis

\footnotetext{
${ }^{5}$ For each country, the CEA with the lowest number in the earliest survey was the starting point, and it was searched through all CEAs in the later survey to find the nearest neighbour. This nearest CEA in the latest survey was excluded when the procedure was repeated for the second CEA in the earliest survey. Similarly, the CEA found in this second step as well as that found in the first step were excluded when a "mate" was searched for the third CEA in the earliest survey, and so on.
} 
of second- and higher-order births), $10 \mathrm{~km}$ (1,973 and 2,128 pairs), and $25 \mathrm{~km} \mathrm{(3,068}$ and 3,353 pairs).

Survey Group D includes the most recent surveys in each country after 2002 for which GPS coordinates of sufficient quality were available. Twenty countries were represented. The average education of all respondents in the up to ten nearest CEAs within a certain distance was considered an indicator of the overall level of education in a relatively small and loosely-defined area surrounding the CEA where the woman lives (and that is smaller than the province, of course). ${ }^{6}$ The distance limits were set to 10 , 25 , or $50 \mathrm{~km}$. The average number of CEAs within these limits was $2.9,5.5$, and 8.2, respectively. Women living in a CEA that has no neigbouring CEAs within the selected limit were excluded from the analysis (41\% when using a $10 \mathrm{~km}$ limit, $12 \%$ when using a $25 \mathrm{~km}$ limit, and 3\% when using a $50 \mathrm{~km}$ limit).

\section{Methods}

For reasons explained below, the analysis is focused on fertility during a rather short period before the interviews. A two-year limit was set (similar results were obtained with a four-year limit) and discrete-time hazard models estimated for this period. More precisely, each woman contributed a series of six-month observation intervals, which tests showed to be sufficiently short. In the first-birth models, the women were followed beginning two years before the survey unless they were younger than 14 at that time, in which case they were followed from age 14. The included covariates referred to the situation at the beginning of these six-month intervals or at interview (see below). It was censored at age 24, when the majority had become mothers. Extending the limit to age 29 added about $9 \%$ to the number of first births, and the results were very similar. ${ }^{7}$

In the multiepisode models that were estimated for second- and higher-order births, the follow-up was from two years before the survey or the time of first birth, whichever was the latest. The "clock" was reset each time a birth occurred within this period of a maximum of two years, in the sense that the variable "duration since last previous birth" was set to zero in that month and the parity variable was increased by one (or more, if multiple births). Because of the obvious censoring at interview, only

\footnotetext{
${ }^{6}$ Generally, the CEAs are not meant to be representative of levels lower than the province or its rural and urban sub-areas.

${ }^{7}$ Many variables affect the timing of first birth, but to a much lesser extent whether a first child is ever born. This shows up as negative effects at low age and positive effects at higher age. Because the research interest often lies in the inclination to have a relatively early first birth, it makes sense to estimate models only for those who are quite young. However, if the whole reproductive age span is included, the effects at low age, when many are still under exposure, may dominate.
} 
women younger than 49 were included. Censoring at age 39 or 44 gave almost the same results.

Although the log odds of having a child (within six months) is modeled, it is common to refer to the exponentiated coefficients in such models as effects on the birth probability (approximately correct when the probability is small) or birth rate. To be more correct, given the inability to control fully for selection effects, one may refer to these exponentiated coefficients as "associations with birth rates or probabilities." For simplicity, expressions such as "associations with first births" are also used below.

When using survey Group A, there were 55,585 births during 669,536 six-month observations in the most recent surveys (10,596 first births during 204,572 observations and 44,989 second- and higher-order births during 464,964 observations). The corresponding numbers in the surveys 8-13 years earlier were 36,453 and 406,992. The number of births in survey Groups B, C (using the $10 \mathrm{~km}$ limit), and D (using the $25 \mathrm{~km}$ limit) were 93,800, 27,222 and 59,758, respectively.

In accordance with common procedures in multilevel analysis (e.g., Goldstein 2003), a random term at the CEA level was included in all models except those that included fixed effects at a somewhat higher level. This term represents a set of unobserved characteristics assumed to be drawn independently for each CEA from the same normal distribution with zero mean and a variance to be estimated (i.e., these characteristics are assumed to be uncorrelated with the observed CEA characteristics). Including such a random term increases standard errors of effects of CEA variables, but has typically very little impact on point estimates (and no impact in linear models; see Snijders and Bosker 1999). The random term models were estimated with aML (Lillard and Panis 2003), while all others were estimated with SAS.

In the models that included average education at a higher level, random terms at that level were not added. Inclusion of a province random term was attempted, but there were capacity problems with aML as well as with MLwiN, which was tried as an alternative. To get an impression of the implications of not including a random term, a model was estimated for about $1 / 4$ of the countries in MLwiN. The standard error of the effect of province education was $72 \%$ larger when the province random term was added than without this term. Inclusion of a random term representing groups of neighbouring CEAs would not be meaningful or feasible within standard multilevel techniques. This is because CEAs are not nested within these groups as they are nested within provinces. Instead, the groups are overlapping. 


\subsection{Included variables}

No attempt is made in this study to identify how community education operates through various individual factors such as knowledge, attitudes, or work opportunities, perhaps via other community factors such as overall income level or women's autonomy. One reason is that there is not relevant data on all these factors. Another is the two-way direction of causality. For example, a higher level of education in a community may gradually drive income levels up and strengthen women's position, but these factors are also determinants of community education, as mentioned earlier. Given this ambiguity, one would not know whether these factors should be seen as common determinants of education and fertility, which ideally should be controlled for, or whether they are causally intermediate factors. The latter should be kept out from some, but not all, models to assess their contribution to a total "causal" effect.

In short, the intention is to get an impression of the total effect of community education - which may operate through a number of mechanisms - by controlling for some observed individual and community factors mentioned below that quite obviously are causally behind education. Unfortunately, the resulting estimates of the community education effects will also reflect that there are unobserved common determinants of education and fertility, as well as a number of factors of importance for fertility that are linked to community education in a two-way causality and that may or may not be available in the data. In most models, unobserved factors at the country level are controlled for by including country dummies. In other models, constant unobserved factors at a level slightly higher than the CEA are controlled for by constructing pairs of CEAs in two surveys that are close to each other, as already mentioned. These constant factors may, for example, include certain aspects of the physical environment or persistent values. With such constant factors controlled for, there may still be a bias (see comment on selection above and concluding comments below).

In addition to community education variables at different levels and the mentioned dummy variables, the models included the age of the woman, the duration since her last previous birth (only in the models for second- and higher-order births), her parity (also only for second- and higher-order births), her religion, her education, whether the CEA in which she lives is urban (defined in the data as being located in a settlement with at least 10,000 inhabitants), and the religious composition of the CEA. The categorization of the included variables should be understood from Table 1. In the models including dummies for pairs of CEAs in two different surveys, a period variable was also included. ${ }^{8}$ When the average education at a level above the CEA was included, a rural-

${ }^{8}$ Otherwise, a lower fertility in the CEAs with high average education might reflect that these CEAs are from the most recent surveys, when fertility may be lower because of general changes throughout the region in certain important determinants. 
urban indicator at that level was included as well, but not the religious composition, which is much less important as a control variable.

The potentially influential other women and men in the CEA or a larger area usually include some of the individual woman's family members, who may have special importance for her fertility. In particular, her husband typically lives in the same CEA. Thus, one reason for a fertility-depressing effect of a high average education among women in the CEA may be that this average indicates a corresponding high average among men, which in turn indicates a high education for her husband, which likely reduces her fertility. However, in models for second- and higher-order births that were estimated only for women who were married at interview, inclusion of husband's education had very little impact of the effects of CEA education (not shown in tables). That said, one should hesitate to condition the modeling on current marital status or include marital status (even if a time-varying variable) in fertility models - and especially for first births - because of the simultaneity in the marriage and fertility decisions and the possible effects of fertility on marital status.

To check whether the effects of CEA education depend on the level of socioeconomic development, five stratified analyses were carried out. First, models were estimated separately for rural and urban areas. Second, models were estimated for women with relatively little education versus all others. Third, a distinction was made between women living in CEAs with relatively low average education and the others. ${ }^{10}$ The last step was to condition on an individual indicator of media exposure and the corresponding CEA average. The media indicator was defined as the sum of positive answers to questions about reading newspapers, watching TV, or listening to radio at least once per week.

Pooling across birth orders, $35 \%$ of the exposure time was in urban areas. The other conditioning variables were defined so that the proportion in the most "modern" category was of the same size. ${ }^{11}$

\footnotetext{
${ }^{9}$ One might argue that earlier fertility levels in the community could affect the average education, because growing up with many siblings may have adverse effects on a child's enrollment and educational progression (e.g. Eloundou-Enyegue and Williams 2006) and because of aggregate-level effects of a high dependency ratio on local economic growth and thus opportunities for educational investments (Kelley and Schmidt 2005). Furthermore, the individual women's fertility may be influenced by this earlier fertility, especially to the extent that it reflects the fertility of their parents (which is particularly likely if there has been little migration). However, when the respondents' average number of siblings was included in supplementary models - based on the large subset of surveys that included this information - there was almost no change in the CEA education effect (not shown).

${ }^{10}$ If a difference appears, it means that the effect of community education is not linear.

${ }^{11}$ These are the distributions: $32 \%$ of the women have education at one of the three highest levels, $35 \%$ live in communities where average education is above 5.5 years, $26 \%$ score two or higher on the individual media indicator, and $32 \%$ live in communities where the average score is $>1.1$. Inclusion of interactions might have been an alternative to the stratified estimation, but preliminary analysis showed that such models would be
} 


\subsection{Potential problems arising because of measurements at interview}

At any point in time, birth rates are influenced by characteristics of the woman and her family at that time and earlier as well as community factors she is exposed to in the place where she lives at that time and those she has been exposed to earlier, wherever she may have lived then. Adding to the complexity, the current situation in a community may reflect characteristics of the community in past years, when the woman herself may have lived elsewhere. For example, availability of modern jobs may partly be a result of the general educational level in the area over several earlier years. With the DHS data, there is little one can do except including characteristics measured at the time of interview. In the best case, these may be seen as reflecting the earlier characteristics and exposures that really matter plus a random error, which will bias estimates towards zero. In the worst case, the characteristics at interview may, to some extent, be influenced by earlier fertility. For example, childbearing may have implications for educational progression. In fact, this particular mechanism is highly relevant in poor countries, where it is common to leave school after having become pregnant (Eloundou-Enyegue 2004). It is primarily the estimated effects of secondary education on first births that will be contaminated by this reverse causality, however. Primary education is typically completed when the follow-up starts, if ever, and in most African settings, women who have already become mothers are not likely to take further education regardless of subsequent childbearing. (As development proceeds and longer education becomes more common, effects of fertility on education may play a more important role, like they have been shown to do in studies from rich countries [Cohen, Kravdal, and Keilman 2011]). More importantly, from the perspective of this study, it is possible that women's family size affects their chance of moving to or remaining in an area where the level of education is high. The restriction of the analysis to a two-year window before the surveys is meant to reduce any such biases.

\subsection{Selection into higher parities}

The specification of the models for higher-order births means that the fertility of bettereducated women is compared with that of less-educated women who have the same age, duration since previous birth and parity. This is reasonable in the sense that it provides us with an estimate of how education affects higher-order births specifically and not one that also reflects an effect through a higher age at first birth. However, there is also a selection problem. To see that, consider a group of relatively young women with one

rather complex because interactions with some of the control variables would have to be included (for example, that between country dummies and the urban-rural indicator). 
child. Those among these women who have relatively high education - which is usually associated with late entry into motherhood - may, for example, have high fecundity or strong preferences for children compared to what is usual in this educational category. This may also increase second- and higher-order birth rates. Similarly, if we compare among those who had their first child at a relatively high age, the better educated are "on time", while having waited so long in spite of having low education may indicate low fecundity or weak childbearing preferences. A similar argument applies to any variable that is strongly linked with first-birth timing, such as, presumably, community education. The problem may, in principle, be handled through joint estimation of models for first- and higher-order births with a common unobserved factor, which according to earlier studies gives more negative effects of education (Kravdal 2007). However, such a procedure is not feasible in this study because it would require a follow-up from age 14, long before the interview where the key variables are measured. One can only keep in mind that the effects of community education on higher-order births are likely more negative or less positive than suggested by the estimates because of this type of selection.

\section{Results}

\subsection{Change over time}

A full set of estimates from a model for first births, based on the most recent round of surveys in Group A, is shown in Panel A of Table 1. Most interestingly, a one-year increase in CEA education is associated with a reduction of 0.0544 in the log odds of having a first birth, which is significantly different from 0 (standard error is 0.0085 ). The estimate for second- and higher-order births is of roughly the same magnitude: 0.0737 (Panel B, Table 1). Exponentiation of these estimates results in values of 0.947 and 0.929 , respectively (Table 2). The corresponding associations in surveys held 8-13 years earlier are 0.937 and 0.957 when taking into account the change in the size of surveys by using country-specific weights as described above (Table 2). As judged from the non-overlapping 95\% confidence intervals, there has been a significant intensification of the association between CEA education and second- and higher-order births, while the association with first births has been stable. 
Table 1: Effects (with standard errors) on log-odds of having a first- or higher-order birth, estimated from the most recent surveys in Group A

\begin{tabular}{|c|c|}
\hline \multicolumn{2}{|c|}{ Panel A: Effects on first birth } \\
\hline Constant & $-1.5894(0.0542)$ \\
\hline \multicolumn{2}{|l|}{ Characteristics of the woman } \\
\hline \multicolumn{2}{|l|}{ Age } \\
\hline $14-16$ & $-2.4428(0.0349)$ \\
\hline $17-19$ & $-0.6472(0.0249)$ \\
\hline $20-22$ & 0 \\
\hline $23-24$ & $-0.0554(0.0364)$ \\
\hline \multicolumn{2}{|l|}{ Education (years) } \\
\hline $0-2$ & 0 \\
\hline $3-6$ & $-0.3080(0.0306)$ \\
\hline $7-8$ & $-0.5201(0.0408)$ \\
\hline $9-10$ & $-0.9593(0.0482)$ \\
\hline $11+$ & $-1.6680(0.0578)$ \\
\hline \multicolumn{2}{|l|}{ Religion } \\
\hline Christian & 0 \\
\hline Muslim & $0.1718(0.0517)$ \\
\hline Other or no religion & $0.0887(0.0506)$ \\
\hline Whether CEA urban & $-0.2458(0.0343)$ \\
\hline Average education in CEA (years) & $-0.0544(0.0085)$ \\
\hline Proportion Muslim in CEA & $-0.0548(0.0823)$ \\
\hline \multicolumn{2}{|l|}{ Proportion other non-Christian } \\
\hline or no religion in CEA & $0.0237(0.1007)$ \\
\hline \multicolumn{2}{|l|}{ Country } \\
\hline Benin & 0 \\
\hline Burkina Faso & $-0.0551(0.0670)$ \\
\hline Cameroon & $0.6827(0.0615)$ \\
\hline Cote d'Ivoire & $-0.8049(0.0705)$ \\
\hline Ghana & $0.1706(0.0883)$ \\
\hline Kenya & $0.7634(0.0751)$ \\
\hline Madagascar & $0.3787(0.0573)$ \\
\hline Malawi & $0.8500(0.0616)$ \\
\hline Mali & $0.3317(0.0689)$ \\
\hline Niger & $0.3677(0.0740)$ \\
\hline Rwanda & $-0.6703(0.0674)$ \\
\hline Senegal & $-0.4242(0.0725)$ \\
\hline Tanzania & $0.5975(0.0725)$ \\
\hline Uganda & $0.7171(0.0692)$ \\
\hline Zambia & $1.0049(0.0782)$ \\
\hline Zimbabwe & $0.7684(0.0757)$ \\
\hline Standard deviation of CEA random term & $0.3775(0.0200)$ \\
\hline
\end{tabular}




\section{Table 1: (Continued)}

\begin{tabular}{|c|c|}
\hline \multicolumn{2}{|c|}{ Panel B: Effects on second and higher-order births } \\
\hline Constant & $-0.7769(0.0372)$ \\
\hline \multicolumn{2}{|c|}{ Characteristics of the woman } \\
\hline \multicolumn{2}{|c|}{ Age } \\
\hline $14-16$ & $-0.4212(0.0963)$ \\
\hline $17-19$ & $-0.1143(0.0294)$ \\
\hline $20-22$ & 0 \\
\hline $23-25$ & $-0.0188(0.0210)$ \\
\hline $26-28$ & $-0.0697(0.0229)$ \\
\hline $29-31$ & $-0.1731(0.0250)$ \\
\hline $32-34$ & $-0.2860(0.0270)$ \\
\hline $35-37$ & $-0.5074(0.0305)$ \\
\hline $38-40$ & $-0.8547(0.0336)$ \\
\hline $41+$ & $-1.7253(0.0361)$ \\
\hline \multicolumn{2}{|c|}{ Duration since last previous birth (years) } \\
\hline 0 & $-3.2757(0.0277)$ \\
\hline 1 & $-0.9238(0.0134)$ \\
\hline 2 & 0 \\
\hline 3 & $-0.0997(0.0157)$ \\
\hline 4 & $-0.3607(0.0199)$ \\
\hline 5 & $-0.6585(0.0259)$ \\
\hline 6 & $-1.0079(0.0351)$ \\
\hline 7 & $-1.2028(0.0451)$ \\
\hline 8 & $-1.4136(0.0555)$ \\
\hline 9 & $-1.7053(0.0711)$ \\
\hline $10+$ & $-2.4017(0.0529)$ \\
\hline \multicolumn{2}{|l|}{ Parity } \\
\hline 1 & $0.1653(0.0203)$ \\
\hline 2 & $0.0224(0.0188)$ \\
\hline 3 & 0 \\
\hline 4 & $-0.0165(0.0208)$ \\
\hline 5 & $0.0224(0.0232)$ \\
\hline $6+$ & $0.0515(0.0228)$ \\
\hline \multicolumn{2}{|c|}{ Education (years) } \\
\hline $0-2$ & 0 \\
\hline $3-6$ & $0.0021(0.0160)$ \\
\hline $7-8$ & $-0.1007(0.0221)$ \\
\hline $9-10$ & $-0.2902(0.0306)$ \\
\hline $11+$ & $-0.3592(0.0360)$ \\
\hline
\end{tabular}


Table 1: (Continued)

\begin{tabular}{ll}
\hline \multicolumn{2}{c}{ Panel B: Effects on second and higher-order births } \\
\hline Religion & 0 \\
Christian & $0.0329(0.0270)$ \\
Muslim & $0.0863(0.0257)$ \\
Other or no religion & $-0.1435(0.0188)$ \\
Whether CEA urban & $-0.0737(0.0046)$ \\
Average education in CEA (years) & $-0.0695(0.0432)$ \\
Proportion Muslim in CEA & \\
Proportion other non-Christian & $-0.2062(0.0490)$ \\
or no religion in CEA & \\
Country & 0 \\
Benin & $-0.1986(0.0342)$ \\
Burkina Faso & $0.2125(0.0355)$ \\
Cameroon & $-0.2009(0.0452)$ \\
Cote d'Ivoire & $0.0199(0.0473)$ \\
Ghana & $0.2991(0.0401)$ \\
Kenya & $-0.1152(0.0299)$ \\
Madagascar & $0.1081(0.0344)$ \\
Malawi & $0.1116(0.0358)$ \\
Mali & $0.0581(0.0377)$ \\
Niger & $0.4503(0.0363)$ \\
Rwanda & $0.0854(0.0382)$ \\
Senegal & $0.2177(0.0348)$ \\
Tanzania & $0.4679(0.0360)$ \\
Uganda & $0.4143(0.0401)$ \\
Zambia & $-0.0992(0.0460)$ \\
Zimbabwe & $0.2336(0.0088)$ \\
Standard deviation of CEA random term &
\end{tabular}

Using the most recent survey in each country (survey Group B), the association between CEA education and first births (Table 3) appears to be sharper than that seen in the most recent years in the foregoing analysis of secular change (which included fewer countries). The confidence intervals overlap, however. For second- and higher-order births, the difference is more pronounced and in the opposite direction. It does not matter much whether weights that reflect the current population size in the respective countries are used. With these weights, associations with first- and higher-order births are 0.932 and 0.964 , respectively. One may refer to these associations as being as representative of the whole region as possible with the DHS data. 
Table 2: $\quad$ Effects (with 95\% CI) of CEA education on odds of having a first- or higher-order birth in groups of surveys separated by 8-13 years (survey group A)

\begin{tabular}{lll}
\hline & Most recent surveys & Surveys 8-13 years earlier $^{12}$ \\
\hline $\begin{array}{l}\text { Effects on first birth } \\
\text { Effects on second- and }\end{array}$ & $0.947^{* * *}(0.931-0.962)$ & $0.937^{* * *}(0.917-0.958)$ \\
higher-order births & $0.929^{* * *}(0.921-0.937)$ & $0.957^{* * *}(0.947-0.968)$ \\
\hline
\end{tabular}

Note: The models also include the woman's age, duration since last previous birth (only in the models for second and higher-order births), parity (only in the models for second and higher-order births), religion and education, whether the CEA is urban, the religious composition in the CEA, country dummies, and a CEA random term.

${ }^{*} p<.10 ;{ }^{* *} p<0.05 ;{ }^{* * *} p<0.01$

Table 3: Effects (with 95\% CI) of CEA education on odds of having a first- or higher-order birth in the most recent survey in each country (survey Group B)

\begin{tabular}{lll}
\hline & $\begin{array}{l}\text { Models with province-specific } \\
\text { weights, i.e., as in all other } \\
\text { models }\end{array}$ & $\begin{array}{l}\text { Models with weights that also } \\
\text { take country population into } \\
\text { account (see text) }\end{array}$ \\
\hline $\begin{array}{l}\text { Effects on first birth } \\
\begin{array}{l}\text { Effects on second- and } \\
\text { higher-order births }\end{array}\end{array}$ & $0.931^{* * *}(0.920-0.942)$ & $0.932^{* * *}(0.922-0.942)$ \\
\hline
\end{tabular}

Note: The models also include the woman's age, duration since last previous birth (only in the models for second and higher-order births), parity (only in the models for second and higher-order births), religion and education, whether the CEA is urban, the religious composition in the CEA, country dummies, and a CEA random term.

${ }^{*} p<.10 ;{ }^{* \star} p<0.05 ;{ }^{* \star *} p<0.01$

\subsection{Conditional effects}

Still using survey Group B, the association between CEA education and first births is much sharper among the approximate third of the women who score high on one of the development indicators than among other women (Table 4). The estimates are 0.85-0.92 and 0.94-0.98, respectively. There are smaller differences with respect to second- and higher-order births: point estimates always suggest the strongest association for the most "modernized" women, but confidence intervals almost or barely overlap.

\footnotetext{
${ }^{12}$ The province-specific weights in the earliest set of surveys are multiplied by country-specific coefficients defined so that each country contributes as much to the results for these years as it does for the most recent years.

${ }^{13}$ If no weights were used, the effects were 0.934 and 0.955 .
} 
Table 4: $\quad$ Effects (with 95\% CI) of CEA education on odds of having a first- or higher-order birth, stratified by five indicators of socioeconomic development (survey Group B)

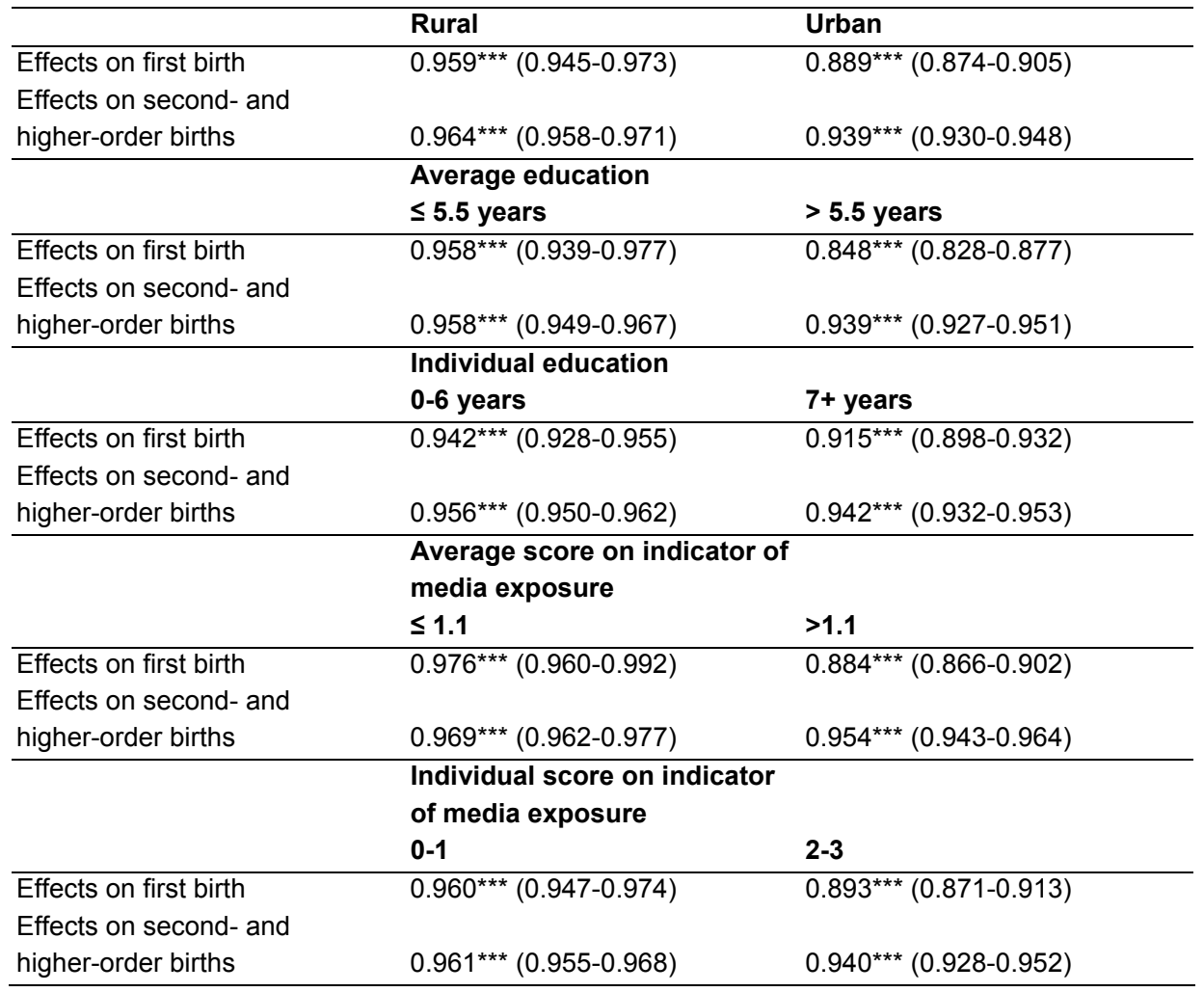

Note: The models also include the woman's age, duration since last previous birth (only in the models for second and higher-order births), parity (only in the models for second and higher-order births), religion and education, whether the CEA is urban, the religious composition in the CEA, country dummies, and a CEA random term.

${ }^{*} p<.10 ;{ }^{* *} p<0.05 ;{ }^{* * *} p<0.01$

\subsection{Controlling for constant unobservables at a level slightly higher than the CEA}

When models are estimated from two surveys with GPS coordinates in each country (survey Group C) with further restriction to pairs of CEAs with 25 observations in total and not more than five kilometers apart, the associations between CEA education and first- and higher-order births are 0.983 and 0.962, respectively (Panel A of Table 5). 
The former is only significant at the $10 \%$ level. Inclusion of dummies (fixed effects) for each pair of CEAs wipes out the association with first births, while the point estimates suggest a very small intensification of the association with second- and higher-order births. The estimates are 0.998 and 0.957 , respectively. If the distance limit is set instead to 10 or $25 \mathrm{~km}$, significant associations appear in the fixed-effects approach both for first- and higher-order births. The associations are around 0.92 and 0.95 , respectively (Panels B and C, Table 5). Without the fixed effects, there is no association between CEA education and first births, and the association with second- and higherorder births is slightly weaker.

Thus, it seems that there is something constant and unobserved that affects CEA education and second- and higher-order births in the same direction. The pattern is less clear for first births: when the distance limit is set to 10 or $25 \mathrm{~km}$, the pattern is the same as for second and higher-order births, but with a five kilometer limit, the effects of the unobserved factors on education and fertility seem to be opposite.

Table 5 Effects (with $95 \%$ CI) of CEA education on odds of having a first- or higher-order birth, according to models that control or not control for constant unobservables (by including fixed effects) at approximately the CEA level (survey Group C)

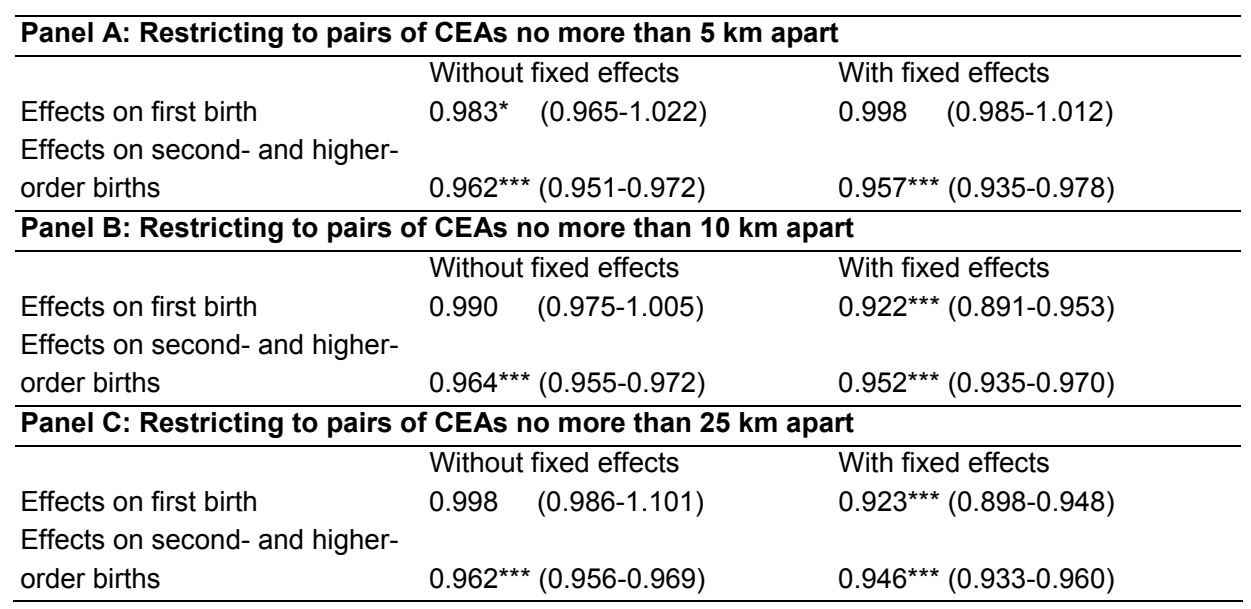

Note: The models also include the woman's age, duration since last previous birth (only in the models for second and higher-order births), parity (only in the models for second and higher-order births), religion and education, whether the CEA is urban, the religious composition in the CEA, and calendar year.

${ }^{*} p<.10 ;{ }^{* *} p<0.05 ;{ }^{* * *} p<0.01$ 


\subsection{Effects of average education in a larger area}

Province education, when included instead of CEA education (using survey Group B), is also associated with the first-birth rate, though more weakly (Table 6). However, when both these community education variables are included, there is an association only with CEA education. Repeating this for second- and higher-order births, the association with province education net of the CEA education is positive. If a province random term is added to these models, the standard error is larger, though an increase of $72 \%$, as found in the model experimentation referred to earlier, still gives a highly significant positive association.

Table 6: Effects (with 95\% CI) of CEA education and province education on odds of having a first- or higher-order birth (survey Group B)

\begin{tabular}{|c|c|c|c|}
\hline & Model 1 & Model 2 & Model 3 \\
\hline \multicolumn{4}{|l|}{ Effects on first birth } \\
\hline CEA education & $0.931^{* * *}(0.920-0.942)$ & $0.933^{* * *}(0.921-0.946)$ & \\
\hline Whether CEA is urban & $0.843^{\star * *}(0.803-0.885)$ & $0.882^{\star * *}(0.834-0.931)$ & \\
\hline Province education & & $1.014 \quad(0.993-1.034)$ & $0.973^{* * *}(0.955-0.991)$ \\
\hline $\begin{array}{l}\text { Proportion in province } \\
\text { who live in urban areas }\end{array}$ & & $0.772^{* * *}(0.685-0.870)$ & $0.651^{* * *}(0.583-0.725)$ \\
\hline \multicolumn{4}{|c|}{ Effects on second- and higher-order births } \\
\hline CEA education & $0.955^{\star \star *}(0.949-0.961)$ & $0.952^{* * *}(0.946-0.959)$ & \\
\hline Whether CEA is urban & $0.851^{* \star *}(0.829-0.875)$ & $0.899^{* * *}(0.873-0.926)$ & \\
\hline Province education & & $1.027^{\star * *}(1.017-1.038)$ & $(0.989-1.008)$ \\
\hline $\begin{array}{l}\text { Proportion in province } \\
\text { who live in urban areas }\end{array}$ & & $0.756^{* * *}(0.707-0.808)$ & $0.662^{* * *}(0.623-0.704)$ \\
\hline
\end{tabular}

Note: The models also include the woman's age, duration since last previous birth (only in the models for second and higher-order births), parity (only in the models for second and higher-order births), religion and education, the religious composition in the CEA, country dummies, and a CEA random term.

${ }^{*} p<.10 ;{ }^{* *} p<0.05 ;{ }^{* \star *} p<0.01$

The final step was to do similar estimations with a focus on neighbouring CEAs included in the surveys rather than the province, using survey Group D. In this sample, associations with CEA education are similar to those estimated from the larger survey Group B (compare first columns of Panel A of Table 7 with Table 3). 
Kravdal: Further evidence of community education effects on fertility in sub-Saharan Africa

Table 7: $\quad$ Effects (with 95\% CI) of average education in CEA and neighbouring CEAs on odds of having a first- or higher-order birth (survey Group D)

\begin{tabular}{|c|c|c|c|}
\hline \multicolumn{4}{|l|}{ Panel A } \\
\hline & Model 1 & Model 2 & Model 3 \\
\hline \multicolumn{4}{|l|}{ Effects on first birth } \\
\hline CEA education & $0.929^{* * *}(0.916-0.942)$ & $0.920^{* * *}(0.904-0.935)$ & \\
\hline Whether CEA urban & $0.834^{* * *}(0.783-0.890)$ & $0.864^{* * *}(0.809-0.923)$ & \\
\hline \multicolumn{4}{|l|}{ Average education in } \\
\hline CEAs within $25 \mathrm{~km}$ & & $1.011 \quad(0.993-1.030)$ & $0.960^{* * *}(0.944-0.975)$ \\
\hline $\begin{array}{l}\text { Proportion in CEAs } \\
\text { within } 25 \mathrm{~km} \text { who live in } \\
\text { urban areas }\end{array}$ & & $0.864^{* * *}(0.791-0.944)$ & $0.794^{* * *}(0.731-0.864)$ \\
\hline \multicolumn{4}{|c|}{ Effects on higher-order births } \\
\hline CEA education & $0.966^{* * *}(0.959-0 .-972)$ & $0.950^{\star * *}(0.941-0.958)$ & \\
\hline Whether CEA urban & $0.841^{* * *}(0.813-0.870)$ & $0.872^{* * *}(0.841-0.904)$ & \\
\hline \multicolumn{4}{|l|}{ Average education in } \\
\hline CEAs within $25 \mathrm{~km}$ & & $1.020^{\star * *}(1.010-1.030)$ & $0.986^{* * *}(0.978-0.995)$ \\
\hline $\begin{array}{l}\text { Proportion in CEAs } \\
\text { within } 25 \mathrm{~km} \text { who live in } \\
\text { urban areas }\end{array}$ & & $0.858^{* * *}(0.818-0.902)$ & $0.813^{* * *}(0.776-0.852)$ \\
\hline \multicolumn{4}{|l|}{ Panel B } \\
\hline \multicolumn{4}{|c|}{ Effects of average education in the CEAs within } \\
\hline & $10 \mathrm{~km}$ & $25 \mathrm{~km}^{14}$ & $50 \mathrm{~km}$ \\
\hline Effects on first birth & $(0.987-1.032)$ & $1.011 \quad(0.993-1.030)$ & $(0.996-1.032)$ \\
\hline $\begin{array}{l}\text { Effects on higher-order } \\
\text { births }\end{array}$ & $(0.989-1.011)$ & $1.020^{\star \star \star}(1.010-1.030)$ & $1.033^{* * *}(1.023-1.042)$ \\
\hline
\end{tabular}

Note: The models also include the woman's age, duration since last previous birth (only in the models for second or higher-order births), parity (only in the models for second or higher-order births), religion and education, whether the CEA is urban, the religious composition in the CEA, country dummies, and a CEA random term. Only the up to ten nearest CEAs within the distance limits are considered.

${ }^{*} p<.10 ;{ }^{* *} p<0.05 ;{ }^{* * *} p<0.01$

There is an association with the average education in the up to ten nearest CEAs within $25 \mathrm{~km}$ on the first-birth rates, but no longer when CEA education (i.e., the average education in the CEA where the woman lives) is included (Panel A, Table 7). For second- and higher-order births there is also an association with the average

\footnotetext{
${ }^{14}$ As in Panel A.
} 
education in these neighbouring CEAs, but the sign changes when CEA education is included.

When a limit of $10 \mathrm{~km}$ is used instead, there is no longer a positive association with education levels in neighbouring CEAs on second- and higher-order births (Panel $\mathrm{B}$, Table 7). Using a limit of $50 \mathrm{~km}$ gives a more positive association with second- and higher-order births, and there is a weak indication of a positive association with first births.

\section{Conclusion}

The overarching goal of this study was to learn more about the importance of community education for fertility. If there really are such effects, expansion of education will reduce fertility more strongly than one would predict from models where only individual education is included.

According to the models estimated from the most recent surveys in all 28 countries in sub-Saharan Africa that are included in the study, a one-year increase in the average education in the census enumeration area where the woman lives (CEA education) reduces the odds of first births by $6.8 \%(=1.0-0.932)$ and the odds of second- and higher-order births by $3.6 \%(=1.0-0.964)$. Among the subset of countries that have had at least one DHS survey after 2002 and one survey 8-13 years previous (in which the associations with CEA education are somewhat different from those seen for all 28 countries), there has been an intensification of the associations with second- and higherorder births, while the association with first births has been stable.

Another important conclusion from the analysis is that associations with CEA education are strongest among women who live in urban areas or who are most advantaged in terms of individual or CEA-level indicators of education or media exposure. This suggests that the association with CEA education is more likely to be strengthened than weakened in the future.

Interestingly, associations with CEA education are significant also when pairs of geographically proximate CEAs in two subsequent surveys were formed and dummies for each pair added. With this approach, constant community factors that are common to the two CEAs, and that may affect education in the two areas as well as fertility, are captured. (Most of the estimates suggest that these constant unobserved factors influence CEA education and fertility in the same direction, but the pattern is not entirely clear.) However, there may also be constant factors that differ between the two CEAs. For example, one CEA may be closer to a large city than the other, leading to higher education as well as lower fertility. This would not have been a problem if there were measurements in exactly the same CEAs in the two surveys. 
With the approach used here as well as the more ideal design based on multiple measurements in each CEA, there are two additional reasons why one should hesitate to interpret the estimated associations as causal effects. First, time-varying unobserved factors, such as local income levels or policies, may affect education as well as fertility. Second, there may be individual-level confounders reflecting selective migration. One example is that a woman who has grown up in a socially advantaged family may have the resources necessary to move to or remain in a high-education area (with potentially higher price levels) and may also have low fertility for other reasons. It is, of course, very difficult to control for all such sources of bias with observational data, and it is hard to see how an experiment realistically could be carried out.

The idea that a woman's fertility may be negatively influenced not only by the level of education within the CEA but also by education among women in a larger area is not supported by the results. When differences in CEA education are controlled for, the second- and higher-order birth rates are positively associated with the average education in the province or the neighbouring CEAs, except if the latter are restricted to lie within $10 \mathrm{~km}$. These neighbouring CEAs are not representative of any particular well-defined area, but the result should still tell us something about the importance of education in an area surrounding, but not very far from, the CEA in which the woman lives. First births are not associated with any of these indicators of education in a larger area.

As explained earlier, effects of community education on second- and higher-order births (and other factors that reduce first-birth rates) may be more negative or less positive than suggested by the estimates because, among those who at any given age are under exposure for a higher-parity transition, a high value of these factors is linked to unobserved factors with positive effect on fertility. This kind of selection may be one reason for the generally weaker associations with community education that are observed for second- and higher-order births than for first births. It is also possible that a less positive or even non-positive association with province education would have appeared if the selection could have been accounted for through joint modeling of firstand higher-order births. That said, there may also be substantively more interesting reasons for less negative or more positive associations with second- and higher-order births than with first births. For example, a possible weakening of the norms prescribing a relatively long period of breastfeeding is relevant only for those who have already become mothers.

Why do associations with education in the province, or in a smaller area surrounding the CEA, appear to be less negative than those with CEA education, or even positive? One possible reason for less negative estimates may be that the effects of social learning which probably involve women in the neighbourhood to a particular extent, are fertility depressing and relatively strong while the more indirect effects that 
may play out also - or primarily - at a higher level are more weakly negative. In principle, the indirect effect could even be positive - as a result of opportunity costs being reduced because of inadequate increase in the number of modern jobs compared to educational expansion - and if it is the education at a relatively high level of aggregation that is most relevant in this mechanism, the observed pattern would make sense.

To summarize, this study has added to the evidence about fertility-depressing effects of a relatively high average education in the census enumeration area where the woman lives (net of her own education) by showing that associations exist also when constant unobserved factors at a slightly higher level are controlled for. However, this approach does not eliminate all potential bias. Furthermore, the associations do not seem to have been attenuated over the last decade. Additionally, since they are not particularly weak at high levels of socioeconomic development, one should not expect them to disappear soon. The local processes appear to be particularly important in the sense that education among women outside the census enumeration area is not negatively associated with fertility.

\section{Acknowledgements}

The financial support from the Hewlett Foundation and the Norwegian Research Council (grant 199475), Torbjørn Eriksen Kravdal's help with the GPS software, and comments from two reviewers are greatly appreciated. 


\section{References}

Balk, D. (1994). Individual and community aspects of women's status and fertility in rural Bangladesh. Population Studies 48(1): 21-45. doi:10.1080/003247203 1000147456.

Baschieri, A. (2007). Effects of modernisation on desired fertility in Egypt. Population, Space and Place 13(5): 353-376. doi:10.1002/psp.454.

Benefo, K.D. (2006). The community-level effects of women's education on reproductive behaviour in rural Ghana. Demographic Research 14(20): 485-508. doi:10.4054/DemRes.2006.14.20.

Benefo, K.D. (2010). Determinants of condom use in Zambia: A multilevel analysis. Studies in Family Planning 41(1): 19-30. doi:10.1111/j.1728-4465.2010.00221.x

Brueckner, J.K. and Largey, A.G. (2008). Social interaction and urban sprawl. Journal of Urban Economics 64(1): 18-34. doi:10.1016/j.jue.2007.08.002.

Chaix, B., Rosvall, M., and Merlo, J. (2007). Recent increase of neighborhood socioeconomic effects on ischemic heart disease mortality: A multilevel survival analysis of two large Swedish cohorts. American Journal of Epidemiology 165(1): 22-26. doi:10.1093/aje/kwj322.

Cohen, J., Kravdal, Ø., and Keilman, N. (2011). Childbearing impeded education more than education impeded childbearing in a cohort among Norwegian women. Proceedings of the National Academy of Sciences. 108(29): 11830-11835. doi:10.1073/pnas.1107993108.

DeRose, L.F. and Kravdal, Ø. (2007). Educational reversals and first-birth timing in sub-Saharan Africa: A dynamic multilevel approach. Demography 44(1): 59-77. doi:10.1353/dem.2007.0001.

DeRose, L.F., Wu, L., and Dodoo, F.N.A. (2010). Inferring gender-power: women's schooling and relative spousal influence in childbearing in Ghana. Genus 66(2): 69-91.

Dodoo, F. N.A. and Frost, A.E. (2008). Gender in African population research: The fertility/reproductive health example. Annual Review of Sociology 34: 431-452. doi:10.1146/annurev.soc.34.040507.134552.

Eloundou-Enyegue, P.M. (2004). Pregnancy-related dropouts and gender inequality in education: A life-table approach and application to Cameroon. Demography 41(3): 509-528. doi:10.1353/dem.2004.0021. 
Eloundou-Enyegue, P. and Williams, L. (2006). Family size and schooling in subSaharan African Settings: A reexamination. Demography 43(1): 25-52. doi:10.1353/dem.2006.0002.

Goldstein, H. (2003). Multilevel Statistical Models, 3rd edition. London: Arnold.

Gupta, N. and Mahy, M. (2003). Adolescent childbearing in sub-Saharan Africa: Can increased schooling alone raise ages at first birth? Demographic Research 8(4): 93-106. doi:10.4054/DemRes.2003.8.4.

Happel, S.K., Hill, J.K., and Low, S.A. (1984). An economic analysis of the timing of childbirth. Population Studies 38(2): 299-311. doi:10.1080/00324728. 1984.10410291.

Hirschman, C. and Young, Y.-J. (2000). Social context and fertility decline in Southeast Asia: 1968-70 to 1988-90. Population and Development Review 26: 11-39.

Hobcraft, J. (2006). The ABC of demographic behaviour: How the interplays of alleles, brains, and contexts over the life course should shape research aimed at understanding population processes. Population Studies 60(2): 153-187. doi:10.1080/00324720600646410.

Jejeebhoy, S.J. and Sathar, Z.A. (2001). Women's autonomy in India and Pakistan: The influence of religion and region. Population and Development Review 27(4): 687-712. doi:10.1111/j.1728-4457.2001.00687.x.

Kelley, A.C. and Schmidt, R.M. (2005). Evolution of recent economic-demographic modeling: A synthesis. Journal of Population Economics 18(2): 275-300. doi:10.1007/s00148-005-0222-9.

Kohler, H.-P., Behrman, J.R., and Watkins, S.C. (2001). The density of social networks and fertility decisions: Evidence from South Nyanza District, Kenya. Demography 38(1): 43-58. doi:10.1353/dem.2001.0005.

Kravdal, Ø. (2002). Education and fertility in sub-Saharan Africa: Individual and community effects. Demography 39(2): 233-250. doi:10.2307/3088337

Kravdal, Ø. (2004). Child mortality in India: The community-level effect of education. Population Studies 58(2): 177-192. doi:10.1080/0032472042000213721.

Kravdal, Ø. (2006). A simulation-based assessment of the bias produced when using averages from small DHS clusters as contextual variables in multilevel models. Demographic Research 15(1): 1-20. doi:10.4054/DemRes.2006.15.1. 
Kravdal, Ø. (2007). Effects of current education on second- and third-birth rates among Norwegian women and men born in 1964: Substantive interpretations and methodological issues. Demographic Research 17(9): 211-246. doi:10.4054 /DemRes.2007.17.9.

Kravdal, Ø. (2009). Mortality effects of average education: A multilevel study of small neighbourhoods in rural and urban areas in Norway. International Journal for Equity in Health 8(41). doi:10.1186/1475-9276-8-41.

Lillard, L. and Panis, C.W.A. (2003). aML Multilevel Multiprocess Statistical Software. Version 2.0., Los Angeles, California: EconWare.

Macro International, Inc. (1996). Sampling manual. DHS-III Basic Documentation No. 6. Calverton, Maryland: Macro International, Inc. http://www.measuredhs.com/ pubs/pdf/AISM5/DHS_III_Sampling_Manual.pdf

Mason, K.O. (1998). Gender and demographic change: What do we know? In: Jones, G.W., Caldwell, J.C., Douglas, R.M., and D'Souza, R.M. (eds.). The Continuing Demographic Transition. Oxford, England: Clarendon Press: 158-182.

McNay, K. Arokiasamy, P., and Cassen, R. (2003). Why are uneducated women in India using contraception? A multilevel analysis. Population Studies 57: 21-40. doi:10.1080/0032472032000061703

Montgomery, M.R. and Casterline, J.B. (1996). Social learning, social influence and new models of fertility. Population and Development Review 22: 151-175. doi:10.2307/2808010.

Moursund, A. and Kravdal, Ø. (2003). Individual and community effects of women's education and autonomy on contraceptive use in India. Population Studies 57(3): 285-301. doi:10.1080/0032472032000137817.

Nahmias, P. and Stecklov, G. (2007). The dynamics of fertility among Palestinians in Israel from 1980 to 2000. European Journal of Population 23(1): 71-99. doi:10.1007/s10680-006-9113-3.

Niraula, B.B. and Morgan, S.P. (1996). Marriage formation, post-marital contact with natal kin and autonomy of women: Evidence from two Nepali settings. Population Studies 50(1): 35-50. doi:10.1080/0032472031000149036.

Pamuk, E.R., Fuchs, R., and Lutz, W. (2011). Comparing relative effects of education and economic resources on infant mortality in developing countries. Population and Development Review 37(4): 637-664. doi:10.1111/j.1728-4457.2011. 00451.x. 
Pickett, K.E. and Pearl, M. (2001). Multilevel analyses of neighbourhood socioeconomic context and health outcomes: A critical review. Journal of Epidemiology and Community Health 55(2): 111-122. doi:10.1136/jech. 55.2.111.

Putnam, R.D. (2000). Bowling Alone: The Collapse and Revival of American Community. New York: Simon \& Schuster.

Snijders, T.A.B. and Bosker, R.J. (1999). Multilevel Analysis. Sage: London.

Stephenson R., Baschieri A., Clements, S., Hennink, M., and Madise, N. (2007). Contextual influences on modern contraceptive use in sub-Saharan Africa. American Journal of Public Health 97(7): 1233-1240. doi:10.2105/AJPH. 2005.071522

Stephenson, R., Beke, A., and Tshibangu, D. (2008). Community and health facility influences on contraceptive method choice in the Eastern Cape, South Africa. International Family Planning Perspectives 34(2): 62-70. doi:10.1363/3406208.

Turrell, G., Kavanagh, A., Draper, G., and Subramanian, S.V. (2007). Do places affect the probability of death in Australia? A multilevel study of area-level disadvantage, individual-level socioeconomic position and all-cause mortality, 1998-2000. Journal of Epidemiology and Community Health 61(1): 13-19. doi:10.1136/jech.2006.046094.

United Nations (2004). World Population Monitoring 2003. Population, Education and Development. New York: Department of Economic and Social Affairs. Population Division. (ST/ESA/SER.A/228) www.un.org/esa/population/ publications/2003monitoring/WorldPopMonitoring 2003.pdf

Yabiku, S.T. (2006). Neighbors and neighborhoods: Effects on marriage timing. Population Research and Policy Review 25(4): 305-327. doi:10.1007/s11113006-9006-5. 


\section{Appendix table: Selection of surveys in Groups A-D}

\begin{tabular}{|c|c|c|c|c|}
\hline & $\begin{array}{c}\text { A: The most } \\
\text { recent survey } \\
\text { and another 8-13 } \\
\text { years earlier }\end{array}$ & $\begin{array}{l}\text { B: The most } \\
\text { recent survey }\end{array}$ & $\begin{array}{l}\text { C: Two surveys } \\
\text { with GPS of } \\
\text { reasonable } \\
\text { quality }\end{array}$ & $\begin{array}{c}\text { D: Most recent } \\
\text { survey with GPS } \\
\text { of reasonable } \\
\text { quality }\end{array}$ \\
\hline \multicolumn{5}{|l|}{ Benin } \\
\hline 1996 & $x$ & & $x$ & \\
\hline 2001 & & & $x$ & $x$ \\
\hline 2006 & $x$ & $x$ & & \\
\hline \multicolumn{5}{|c|}{ Burkina Faso } \\
\hline 1993 & $x$ & & & \\
\hline 1999 & & & $x$ & \\
\hline 2003 & $x$ & $x$ & $x$ & $\mathrm{X}$ \\
\hline \multicolumn{5}{|c|}{ Cameroon } \\
\hline 1991 & $x$ & & & \\
\hline \multicolumn{5}{|l|}{1998} \\
\hline 2004 & $x$ & $x$ & & $x$ \\
\hline \multicolumn{5}{|l|}{ Chad } \\
\hline \multicolumn{5}{|l|}{1997} \\
\hline 2004 & & $x$ & & \\
\hline \multicolumn{5}{|c|}{ Congo-BR } \\
\hline 2005 & & $x$ & & \\
\hline \multicolumn{5}{|c|}{ Congo-DR } \\
\hline 2007 & & $x$ & & $x$ \\
\hline \multicolumn{5}{|c|}{ Cote d'Ivoire } \\
\hline 1994 & $x$ & & & \\
\hline \multicolumn{5}{|l|}{1999} \\
\hline 2005 & $x$ & $x$ & & \\
\hline \multicolumn{5}{|l|}{ Ethiopia } \\
\hline 2000 & & & $x$ & \\
\hline 2005 & & $x$ & $x$ & $x$ \\
\hline \multicolumn{5}{|l|}{ Ghana } \\
\hline \multicolumn{5}{|l|}{1988} \\
\hline \multicolumn{5}{|l|}{1993} \\
\hline 1998 & $x$ & & & \\
\hline
\end{tabular}




\section{Appendix table: (Continued)}

\begin{tabular}{|c|c|c|c|c|}
\hline & $\begin{array}{c}\text { A: The most } \\
\text { recent survey } \\
\text { and another } 8-13 \\
\text { years earlier }\end{array}$ & $\begin{array}{l}\text { B: The most } \\
\text { recent survey }\end{array}$ & $\begin{array}{c}\text { C: Two surveys } \\
\text { with GPS of } \\
\text { reasonable } \\
\text { quality }\end{array}$ & $\begin{array}{c}\text { D: Most recent } \\
\text { survey with GPS } \\
\text { of reasonable } \\
\text { quality }\end{array}$ \\
\hline 2003 & & & $\mathrm{X}$ & \\
\hline 2008 & $x$ & $x$ & $x$ & $x$ \\
\hline \multicolumn{5}{|l|}{ Guinea } \\
\hline 1999 & & & $x$ & \\
\hline 2005 & & $x$ & $x$ & $x$ \\
\hline \multicolumn{5}{|l|}{ Kenya } \\
\hline \multicolumn{5}{|l|}{1989} \\
\hline \multicolumn{5}{|l|}{1993} \\
\hline 1998 & $x$ & & & \\
\hline \multicolumn{5}{|l|}{2003} \\
\hline 2009 & $x$ & $x$ & & $x$ \\
\hline \multicolumn{5}{|l|}{ Lesotho } \\
\hline 2004 & & & $x$ & \\
\hline 2010 & & $x$ & $\mathrm{X}$ & $x$ \\
\hline \multicolumn{5}{|l|}{ Liberia } \\
\hline \multicolumn{5}{|l|}{1986} \\
\hline 2007 & & $x$ & & $x$ \\
\hline \multicolumn{5}{|c|}{ Madagascar } \\
\hline \multicolumn{5}{|l|}{1992} \\
\hline 1997 & $x$ & & $x$ & \\
\hline \multicolumn{5}{|l|}{2004} \\
\hline 2009 & $x$ & $x$ & $x$ & $x$ \\
\hline \multicolumn{5}{|l|}{ Malawi } \\
\hline 1992 & $x$ & & & \\
\hline 2000 & & & $x$ & \\
\hline 2004 & $\mathrm{X}$ & $\mathrm{X}$ & $x$ & $\mathrm{X}$ \\
\hline \multicolumn{5}{|l|}{ Mali } \\
\hline \multicolumn{5}{|l|}{1987} \\
\hline 1996 & $x$ & & & \\
\hline 2001 & & & $x$ & \\
\hline 2006 & $\mathrm{X}$ & $\mathrm{X}$ & $x$ & $x$ \\
\hline
\end{tabular}




\section{Appendix table: (Continued)}

\begin{tabular}{|c|c|c|c|c|}
\hline & $\begin{array}{c}\text { A: The most } \\
\text { recent survey } \\
\text { and another 8-13 } \\
\text { years earlier }\end{array}$ & $\begin{array}{l}\text { B: The most } \\
\text { recent survey }\end{array}$ & $\begin{array}{c}\text { C: Two surveys } \\
\text { with GPS of } \\
\text { reasonable } \\
\text { quality }\end{array}$ & $\begin{array}{c}\text { D: Most recent } \\
\text { survey with GPS } \\
\text { of reasonable } \\
\text { quality }\end{array}$ \\
\hline \multicolumn{5}{|c|}{ Mozambique } \\
\hline \multicolumn{5}{|l|}{1997} \\
\hline 2003 & & $x$ & & \\
\hline \multicolumn{5}{|l|}{ Namibia } \\
\hline \multicolumn{5}{|l|}{1992} \\
\hline 2000 & & & $x$ & \\
\hline 2007 & & $x$ & $x$ & $x$ \\
\hline \multicolumn{5}{|l|}{ Niger } \\
\hline \multicolumn{5}{|l|}{1992} \\
\hline 1998 & $x$ & & & \\
\hline 2006 & $x$ & $x$ & & \\
\hline \multicolumn{5}{|l|}{ Nigeria } \\
\hline \multicolumn{5}{|l|}{1990} \\
\hline \multicolumn{5}{|c|}{1999 low quality } \\
\hline 2003 & & & $x$ & \\
\hline 2008 & & $x$ & $x$ & $x$ \\
\hline \multicolumn{5}{|l|}{ Rwanda } \\
\hline 1992 & $x$ & & & \\
\hline \multicolumn{5}{|l|}{2000} \\
\hline 2005 & $x$ & $x$ & & $x$ \\
\hline \multicolumn{5}{|l|}{ Senegal } \\
\hline \multicolumn{5}{|l|}{1986} \\
\hline \multicolumn{5}{|l|}{1993} \\
\hline 1997 & $x$ & & $x$ & \\
\hline 2005 & $x$ & $x$ & $x$ & $x$ \\
\hline \multicolumn{5}{|c|}{ Sierra Leone } \\
\hline 2008 & & $x$ & & \\
\hline \multicolumn{5}{|c|}{ Swaziland } \\
\hline 2007 & & $x$ & & \\
\hline
\end{tabular}




\section{Appendix table: (Continued)}

\begin{tabular}{|c|c|c|c|c|}
\hline & $\begin{array}{c}\text { A: The most } \\
\text { recent survey } \\
\text { and another } 8-13 \\
\text { years earlier }\end{array}$ & $\begin{array}{l}\text { B: The most } \\
\text { recent survey }\end{array}$ & $\begin{array}{c}\text { C: Two surveys } \\
\text { with GPS of } \\
\text { reasonable } \\
\text { quality }\end{array}$ & $\begin{array}{c}\text { D: Most recent } \\
\text { survey with GPS } \\
\text { of reasonable } \\
\text { quality }\end{array}$ \\
\hline \multicolumn{5}{|c|}{ Tanzania } \\
\hline \multicolumn{5}{|l|}{1992} \\
\hline \multicolumn{5}{|l|}{1996} \\
\hline 1999 & $x$ & & & \\
\hline \multicolumn{5}{|l|}{2005} \\
\hline 2010 & $x$ & $x$ & & \\
\hline \multicolumn{5}{|l|}{ Uganda } \\
\hline 1995 & $x$ & & & \\
\hline 2001 & & & $x$ & \\
\hline 2006 & $x$ & $x$ & $x$ & $x$ \\
\hline \multicolumn{5}{|l|}{ Zambia } \\
\hline \multicolumn{5}{|l|}{1992} \\
\hline 1996 & $x$ & & & \\
\hline \multicolumn{5}{|l|}{2002} \\
\hline 2007 & $x$ & $x$ & & $x$ \\
\hline \multicolumn{5}{|c|}{ Zimbabwe } \\
\hline \multicolumn{5}{|l|}{1988} \\
\hline 1994 & $x$ & & & \\
\hline 1999 & & & $x$ & \\
\hline 2006 & $x$ & $x$ & $x$ & $x$ \\
\hline
\end{tabular}


Kravdal: Further evidence of community education effects on fertility in sub-Saharan Africa 